\title{
Correlation between Sleep Disorders and Sleepy Drivers
}

\author{
Ki-Bong Kim ${ }^{1}$, Hyun-Ho Sung ${ }^{2}$, Sang-Nam Park ${ }^{3}$, Bok-Jo Kim ${ }^{3}$, and Chang-Eun Park ${ }^{4}$ \\ ${ }^{1}$ Section of Neurophysiology Laboratory, Samsung Medical Center, Seoul 06351, Korea \\ ${ }^{2}$ Department of Clinical Laboratory Science, Dongnam Health University, Suwon 16328, Korea \\ ${ }^{3}$ Department of Clinical Laboratory Science, Kyungwoon University, Gumi 39160, Korea \\ ${ }^{4}$ Department of Biomedical Laboratory Science, Namseoul University, Cheonan 31020, Korea
}

\section{수면장애와 졸음운전의 상관성}

\author{
김기봉 ${ }^{1}$, 성현호 $^{2}$, 박상남 $^{3}$, 김복조 $^{3}$, 박창은 $^{4}$ \\ ${ }^{1}$ 삼성서울병원 신경과검사실, ${ }^{2}$ 동남보건대학교 임상병리과, ${ }^{3}$ 경운대학교 임상병리학과, ${ }^{4}$ 남서울대학교 임상병리학과
}

\begin{abstract}
This study aims to identify the prevalence of sleep related disease in those who experienced car accidents caused by drowsy driving. To this end, a survey of usual sleep habits, polysomnography, and multiple sleep latency tests were conducted in 34 persons who experienced an accident after normal sleep (Group 1), 22 persons who experienced an accident after abnormal sleep (Group 2), and 17 persons who was proven to be normal as a result of polysomnography and had no accident (Group 3). In all, 192 persons responded to the preliminary survey and the results were compared and analyzed. Crossover analysis was conducted to test the homogeneity of statistical characteristics, and the physical characteristics by age were analyzed. In the survey of sleeping habits, there was a significance between groups in how often they woke up while asleep $(p<0.01)$, how difficult it was to go back to sleep again after waking up from sleep $(p<0.05)$, how early they woke up in the morning ( $p<0.05$ ), how difficult it was to get up in the morning $(p<0.05)$, how sleepy they felt in the daytime $(p<0.01)$, and how tired they felt in the daytime $(p<0.01)$. Furthermore, among 56 subjects who had an accident during drowsy driving, $94.6 \%$ ( 53 persons) were found to have sleep related diseases. This suggests that car accidents during drowsy driving is not simply caused by temporary lack of sleep but by sleep related diseases even when sleep is adequate, leading to car accidents. Therefore, this study is significant identifying the association between car accidents during drowsy driving and sleep related disorders. Furthermore, the data would be considered basic to prepare social measures against drowsy driving related to such sleep related disorders.
\end{abstract}

Keywords: Drowsy driving, Daytime sleepiness, Sleep apnea, Multiple sleep latency test

This is an Open Access article distributed under the terms of the Creative Commons Attribution Non-Commercial License (http://creativecommons.org/licenses/by-nc/4.0) which permits unrestricted non-commercial use, distribution, and reproduction in any medium, provided the original work is properly cited.

Copyright @ 2015 The Korean Society for Clinical Laboratory Science. All rights reserved.
Corresponding author: Chang-Eun Park Department of Biomedical Laboratory Science, Namseoul University, Cheonan 31020, Korea Tel: 82-41-580-2722

E-mail: eun2777@hanmail.net

Received: October 8, 2015

Revised $1^{\text {st. }}$ October 12, 2015

Revised 2 ${ }^{\text {nd }}$ : October 12, 2015

Accepted: October 12, 2015
서 론

교통사고는 다양한 원인에 의해 발생하는데(Pandi-Perumal 등, 2006), 첫 번째 원인은 전체 교통사고 원인의 약 1 25\%를 차지 하고 있는 졸음운전으로 알려져 있다(Ward 등, 2013). 그러나, 졸 음운전에 대해서는 아직 사회적 인식이 부족하다(Jo와 Lee, 2014).
졸음운전의 가장 대표적인 원인은 수면의 결핍(lack of sleep time)과 수면의 연속성 결여(sleep fragmentation) 때문이며(Lee, 2003), 이러한 수면 시간의 감소로 인한 졸음운전은 환경 및 습관의 개선으로 해결이 가능하지만, 수면관련 질환으로 치료 중인 사람이 나 또는 치료를 받지 않은 사람에게 나타나는 수면의 연속성 결여 는 환경이나 습관의 개선으로 해결이 어렵고, 치사율이 높은 교통 
사고가 발생할 가능성이 크다고 보고되었다(Siedlecka 등, 2012). 졸음운전사고의 발생은 수면 중 무호흡-저 호흡지수가 높은 사람 이나, 또는, 운전 중에 느끼는 졸림의 정도가 심한 사람일수록 높아 진다고 알려져 있다(Choi와 Kim, 2013). 수면무호흡증은 수면 중 호흡의 중단으로 산소 공급이 저하되고, 수면의 연속성이 이어지지 않으며, 수면의 질 저하와 주간 졸음증을 유발하게 된다(Lee, 2003). 기면증 또한, 수면과 각성의 주기 장애가 있는 질환으로 주 간졸음증을 유발한다. 기면증을 치료하지 않으면 자신의 생각과상 관없이 2 3시간 간격으로 10 20분간 급작한 졸음에 빠지게 되 고, 갑자기 몸에 힘이 빠지는 탈력발작(cataplexy)에 의해서 교통 사고가 발생할 수 있다고 보고되었다(Siedlecka 등, 2012). 한 해에 발생하는 졸음운전에 의한 교통사고 사망률과 직 - 간접적인 피해 를 고려해 볼 때, 매우 중요한 문제이지만 아직까지 국내의 졸음운 전에 대한 분류 조사는 미비한 실정이다(Collop 등, 2011).

본 연구에서는 졸음운전 교통사고를 경험한 사람 중에서 정상적 인 수면시간을 갖은 대상 군과 수면 시간이 부족한 대상 군에서 수 면다원검사의 결과가 정상 판정을 받은 군과 비교하여 졸음운전사 고와 수면관련 질환의 상관성을 관찰하고자 하였다.

\section{재료 및 방법}

\section{1. 연구대상}

연구의 대상은 2014년 8월부터 12월까지 서울소재 1개 종합병 원 수면센터를 방문하여 설문에 응답한 200명의 성인 중에서 운전 을 하지 않는 사람을 제외한 192명을 대상으로 조사하였다(Table 1). 이들 중 졸음교통사고를 경험한 군 56 명과 검사결과 정상이면 서 교통사고를 경험하지 않은 군 17명을 대상으로 조사하였으며, 교통사고를 경험한 군 56명 중에서 사고 전날 6시간 이상 정상수면 을 취한 34명(Group 1), 사고 전날 6시간 이하 수면을 취한 22명 (Group 2), 검사 결과가 정상이면서 교통사고를 경험하지 않은 17 명(Group 3)로 분류하였다. 그리고 본 연구에 포함된 대상자는 모 두 자발적 동의를 하였고, 수면 관련 질환을 알아보기 위하여 수면
다원검사(PSG; Polysomnography study), 다중수면잠복기검사 (MSLT; Multiple sleep latency test)를 시행하였다.

\section{2. 수면 습관에 대한 설문}

수면습관은 평상 시 수면습관에 관한 평가로 평균 수면시간, 평 일과 주말의 수면 시간 차이, 잠자리에 누운 후잠이 들 때까지 걸리 는 시간, 주관적인 수면의 문제점, 수면 중 특이사항 및 낮의 졸림 정 도 등을 파악하였고 수면과 운전과의 관계에서는 졸음운전 사고 경 험과 평상 시 수면시간, 사고 전날 수면시간, 졸음운전사고 시 총운 전 시간 및 현재의 수면 습관이 운전에 얼마나 영향 주고 있는지에 대해 설문을 시행하였다.

\section{3. 수면의 분류 및 질환판정}

수면의 분류 및 수면질환의 판정은 미국수면의학회(AASM; American academy of sleep medicine)의 수면 분류법에 따라 분 석하고, 신경과 수면 전문의사가 최종 판정하였다. 수면의 단계와 각성 빈도를 측정하여 수면의 질을 평가하기 위해서 뇌파(EEG; Electroencephalography) 전극배치법(10 20 system)에 따라 $\mathrm{F} 3, \mathrm{~F} 4, \mathrm{C} 3, \mathrm{C} 4, \mathrm{O} 1, \mathrm{O} 2$ 의 뇌파전극을 사용하였고, 기준전극으로

Table 1. General characteristic of attendees

\begin{tabular}{|c|c|c|c|c|}
\hline Age group & Gender & N (\%) & $M \pm S D$ & $x^{2} / p$ \\
\hline \multirow[t]{2}{*}{ All } & Male & $169(80.5)$ & $47.47 \pm 10.05$ & $2.452 / .784$ \\
\hline & Female & $23(12.0)$ & $50.39 \pm 9.46$ & \\
\hline \multirow[t]{2}{*}{$\sim 20$} & Male & $1(0.5)$ & $18.00 \pm 0.00$ & \\
\hline & Female & $0(0.0)$ & - & \\
\hline \multirow[t]{2}{*}{$21 \sim 30$} & Male & $10(5.2)$ & $27.60 \pm 2.22$ & \\
\hline & Female & $2(1.0)$ & $30.00 \pm 0.00$ & \\
\hline \multirow[t]{2}{*}{$31 \sim 40$} & Male & $30(15.6)$ & $35.47 \pm 3.26$ & \\
\hline & Female & $2(1.0)$ & $37.50 \pm 2.12$ & \\
\hline \multirow[t]{2}{*}{$41 \sim 50$} & Male & $55(28.6)$ & $46.56 \pm 2.81$ & \\
\hline & Female & $6(3.1)$ & $47.50 \pm 2.58$ & \\
\hline \multirow[t]{2}{*}{$51 \sim 60$} & Male & $62(32.3)$ & $54.73 \pm 2.64$ & \\
\hline & Female & $11(5.7)$ & $55.70 \pm 2.79$ & \\
\hline \multirow[t]{2}{*}{$60 \sim$} & Male & $11(5.7)$ & $64.64 \pm 3.07$ & \\
\hline & Female & $2(1.0)$ & $63.00 \pm 2.82$ & \\
\hline
\end{tabular}

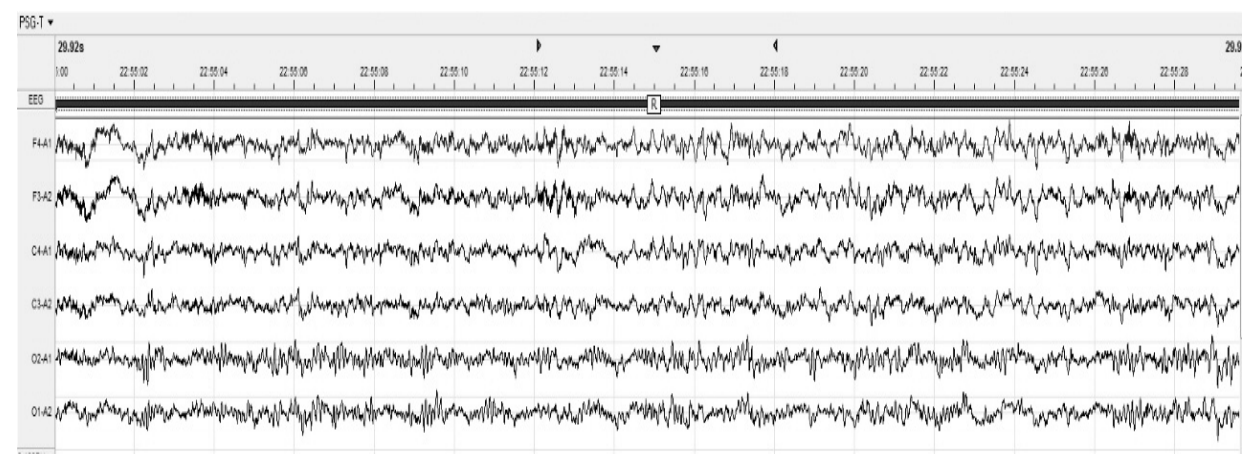

Fig. 1. EEG electrodes for sleep stage classification. The F3, F4 waves is frontal activity, C3, C4 wave of the central activity and $01, \mathrm{O} 2$ wave is occipital activity (alpha rhythm). This record is sensitivity $5 \sim 7 \mu \mathrm{V} / \mathrm{mm}$, HF (high filter) $70 \mathrm{~Hz}$, LF (low filter) 0.3 $\mathrm{Hz}$, paper speed $10 \mathrm{~mm} / \mathrm{sec}(30$ sec/page). 


\section{$\mathrm{M} 1$ 와 M2를 사용하였다(Fig. 1).}

REM (Rapid eye movement) 수면에서 안구의 수평운동을 관 찰하기 위해서 좌우 눈가에서 $1 \mathrm{~cm}$ 씩 상방과 하방으로 전극을 부 착하고, 안구의 상하 움직임을 관찰하기 위하여 안와상연(supraorbital)과 안와하연(infraorbital)에 전극을 추가로 부착하여 기 록하였다(Fig. 2).

$\mathrm{REM}$ 수면 분류를 위하여 턱 위(mentalis)와턱 아래(sub-mentalis) 에 chin EMG (Electromyography) 전극 2개를 부착하고, 야간 근 연축(noctural myoclonus)에 의한 각성반응(arousal reaction)을 기록하기 위해서 앞정강근(tibialis anterior EMG)에 좌, 우 각각 2 개의 전극을 부착하였다. 자발적 호흡노력(respiratory effort)을 관찰하기 위해서 늑골사이(intercostal)에 EMG 전극 2개를 추가로
부착하여 기록하였다(Fig. 3).

수면 중 호흡상태의 관찰은 Fig. 4 와 같이, 코의 온도센서와 압력 센서를 동시에 사용하였고, 가슴과 복부에 벨트로 된 압력 측정기 (strain gauge)를 사용하여 호흡근육의 자발적 호흡노력을 기록하 였다. 기타 혈중 산소포화도 $\left(\mathrm{O}_{2}\right.$ saturation), 코골이(snoring), 심 전도(EKG; Electrocardiogram), 체위 등을 수면과 동시에 기록하 여 수면의 질을 측정하였다.

연구 대상자들은 평소 수면 습관에 따라 잠자리에 들었고, 총 수 면시간(TST; Total sleep time)이 6시간 이상이 되도록 배려하였 다. 연구대상자의 총 수면 시간을 미국수면의학회의 수면분류법에 따라 $\mathrm{S} 1, \mathrm{~S} 2, \mathrm{~S} 3$ 및 REM 수면으로 분류하였다. 또한, 안정된 수면을 방해하는 코골이, 수면 무호흡, 다리 움직임(PLMD; Periodic limb
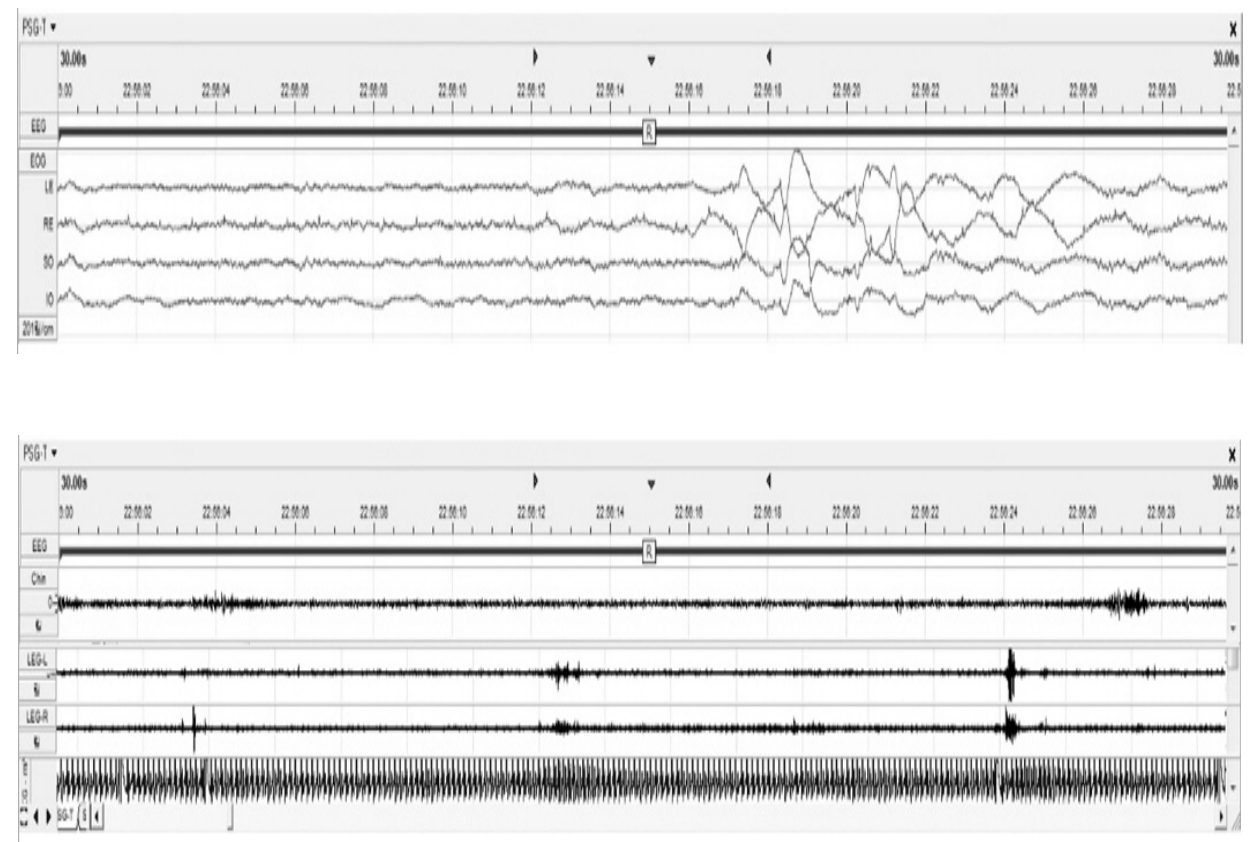

Fig. 2. The channel for identifying eye movement. Upper/downward and leftward/rightward movement of pupils was analyzed by using 4 electrodes. This record shows the movement of the pupils during the REM sleep.
Fig. 3. The electrodes for EMG measurements. The chin EMG (mentalissubmentalis muscle), tibialis anterior EMG and intercostal EMG. This recorde is sensitivity $50 \mu \mathrm{V}$, HF (high filter) 30 35 Hz, LF (low filter) $0.3 \mathrm{~Hz}$.

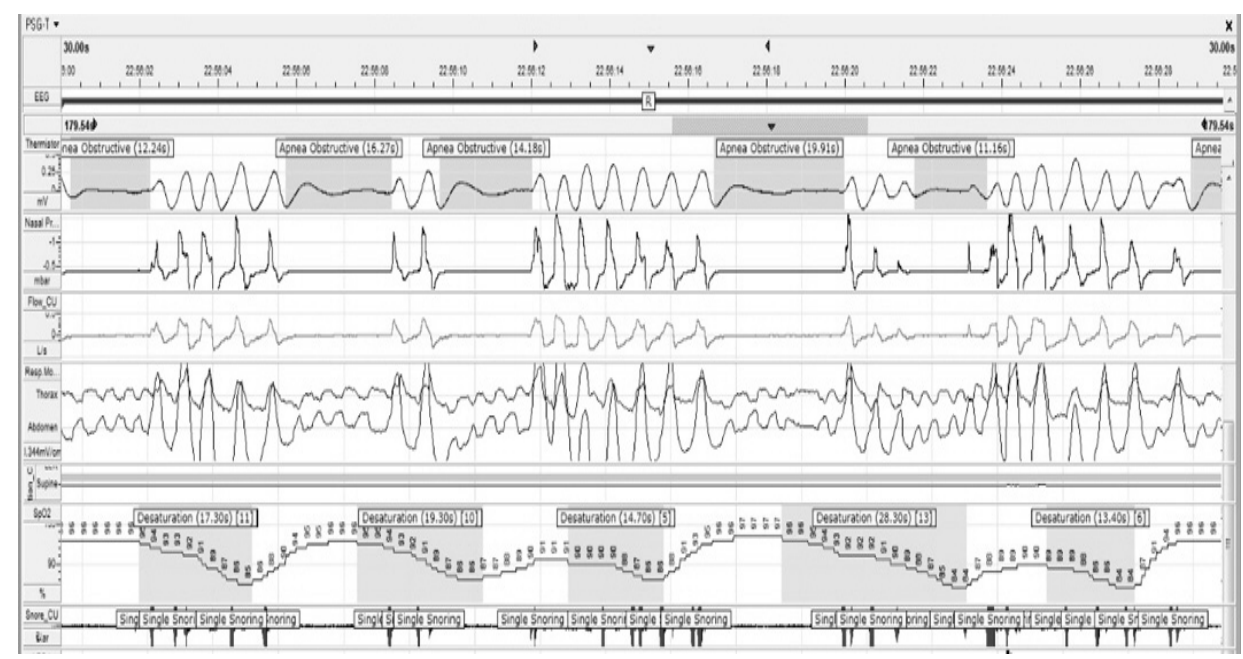

Fig. 4. A sensor for measuring respiratory effort. This record shows the air flow (nasal thermistor and pressure) and respiratory effort measured in the chest and abdomen, and measurements of oxygen saturation $\left(\mathrm{SpO}_{2}\right)$ and snoring. This record related to obstructive sleep apnea patients indicates that oxygen saturation fell as a result of blocked respiratory flow towards the upper airway. 
movement during sleep), 체위 등을 분석하여 Fig. 5 와 같이 다이 아그람을 작성하고, 잠이 들기까지의 시간(SL; Sleep latency), 잠 이 들고 첫 번째 REM 수면까지의 시간(RL; REM latency), 각성반 응지수(TAI; Total arousal index)와 무호흡지수(AHI; Apnea hypopnea index)를 계산하였다.

S1 (stage 1)=얕은 수면(정상 성인 : TST의 10\% 이하)

S2 (stage 2)=중간 수면(정상 성인 : TST의 44 59\%)

S3 (stage 3)=깊은 수면(성인 기준 정상 : TST의 9.5 12\%)

$\mathrm{TAI}=$ 총 arousal 수/(TST/ 60)

AHI=(총 apnea 수+총 hypopnea 수)/(TST/ 60)

주간 졸음증 측정을 위해서 다중수면잠복기검사를 시행하였고, 검사 후, 미국수면의학회의 수면 분류법에 따라서 분석하고, 신경
과 수면 전문의사가 최종 판정하였다. 수면다원검사가 끝난 후, 수 면단계를 분류할 수 있는 뇌파전극(F3, F4, C3, C4, O1, O2, M1, $\mathrm{M} 2$ )과 REM 수면 판단을 위한 안구운동(EOG)전극, mentalis와 sub-mentalischin의 근전도 전극을 남기고 모두 제거하였다. 그 리고 완전한 각성이 유지된 상태에서 30 분 동안 수면을 유도하고, 1 시간 30 분 동안 다시 각성을 유지하는 2 시간의 검사 주기를 5 회 반복하여 실시하였다(Fig. 6). 각각의 검사주기에서 수면을 유도한 후 잠이 들기까지 걸린 시간(sleep latency)의 평균(mean sleep latency)을 구하였고, 잠이 든 후 REM수면이 나올 때까지 걸린 시 간(REM sleep latency)의 평균(mean REM sleep latency)을 계산 하였다. 5 회 반복한 검사 중에서 SOREM (sleep onset REM)이 2회 이상 나오고, mean REM sleep latency가 <15 min 가 충족이 되 면 기면증(narcolepsy)으로 진단하였다.

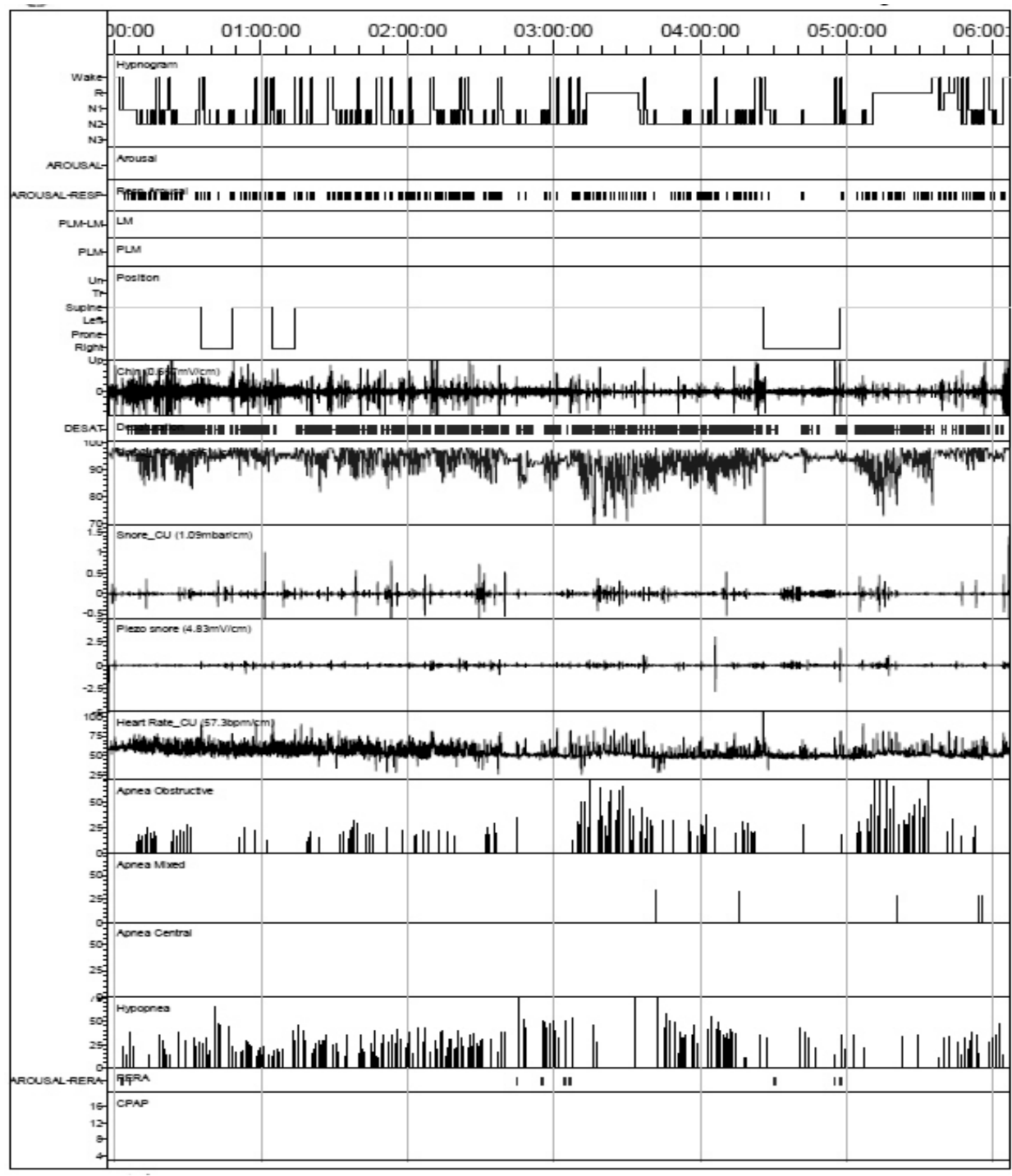

Fig. 5. The graphical representation of the sleep state of obstructive sleep apnea patients for 6 hours and 10 minutes. Classification and analysis of EEG with arousal reaction, PLMD, body position, $\mathrm{SpO}_{2}$, snoring, heart rate, respiration event, etc., is displayed can evaluate the aspects of the overall sleep. 
Mean sleep latency=sleep latency의 합/ 검사 시행 수

Mean REM sleep latency=REM sleep latency의 합/ SOREM 수

다중수면잠복기 검사를 위해서 대상자들은 당일 심한 운동 및 카페인이 함유된 음료를 제한하였고, 자극제 또는, REM수면 억제 약물은 2주 전부터 중단하였다. 각각의 검사 주기에서 30 분 동안 수면 유도 후, 1 시간 30 분 동안 잠을 잘 수 없도록 관리하였다.

\section{4. 통계 분석}

통계의 자료분석은 SPSS, PC. Version 21.0 (SPSS Inc, Chicago, IL, USA)프로그램을 사용하였다. 연구대상자들의 인구 통계학적 특성의 동질성을 검정하고자 교차분석을 시행하였고, 연 령대별 신체적 특성을 분석하고 변수에 따른 모든 정량데이터와수 면다원검사결과의 차이를 검정하기 위해 평균(M)과 표준편차(SD) 를 산출하여 독립 t-검정과 일원배치분산분석을 실시하였다. 각각 의 설문 변인에 따른 차이를 검정하기 위해 교차분석을 통해 카이 제곱검정을 실시하였다. 그리고 모든 통계적 유의수준은 $p=0.05$ 로 설정하였다.

\section{결 과}

\section{1. 수면 설문의 분석}

연구대상자의 평소 수면 시간에 대한 설문 결과는 Table 2과 같

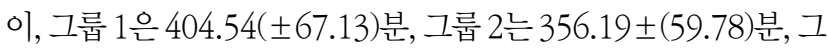
룹 3은 336.00 \pm (108.87)분이었다. 그룹 1은 그룹 2보다 그룹 2는 그룹 3 보다 수면시간이 길게 나타났으며, 그룹 1 과 3 에서 유의한 차이가 있었다 $(p<0.05)$.

Table 3의 평소 수면 습관에 관한 주관적 질문에서 코골이(그룹 $1>$ 그룹2>그룹3) ( $p<0.05)$, 수면무호흡증(그룹1>그룹2>그룹 3) ( $p<0.01$ ), 수면 중 꿈을 꾸는 여부(그룹2>그룹1>그룹3) ( $p<$ 0.05)에 관한 설문 결과에서도 그룹 간에 독립된 집단으로 유의성 이 확인되었다. 또한, 수면 중 각성(그룹2>그룹1>그룹3) ( $p<$ 0.01 ), 수면 각성 후 재 수면이 어려운 정도(그룹1>그룹2>그룹3) $(p<0.05)$, 아침에 일찍 잠이 깨는 정도(그룹 $1>$ 그룹 $2>$ 그룹3) $(p<$ $0.05)$, 아침에 기상하기 어려운 정도(그룹1>그룹2>그룹3) ( $p<$ $0.05)$, 낮에 졸리운 정도(그룹1>그룹 $2>$ 그룹3) $(p<0.01)$, 낮에 피곤한 정도(그룹 $1>$ 그룹2>그룹3) $(p<0.01)$ 에 관한 설문 결과

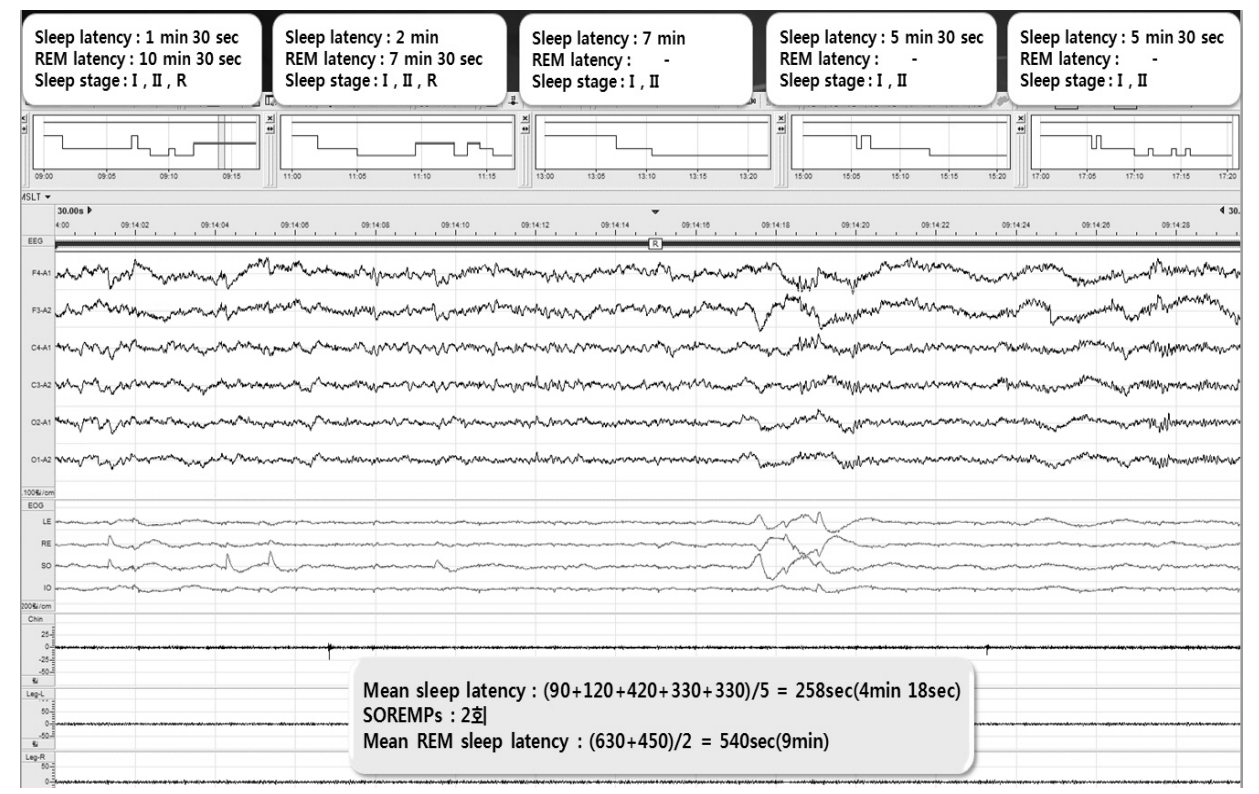

Fig. 6. The records from multiple sleep latency test (MSLT). They were carried out 5 times based on time cycle. The patients were diagnosed with narcolepsy as they showed 2 episodes of sleep-onset REM sleep (SOREM) with mean REM latency $<15$ $\min (9 \mathrm{~min})$.

Table 2. Differences of average daily sleep time among groups

\begin{tabular}{cccccc}
\hline & Total & Group 1 & Group 2 & Group 3 $^{\mathrm{b}}$ & $\mathrm{F} / p$ \\
\cline { 2 - 5 } & $\mathrm{N}=192$ & $\mathrm{~N}=34$ & $\mathrm{~N}=22$ & $\mathrm{~N}=17$ & \\
\hline Average daily sleep time $(\mathrm{min})$ & $323.02 \pm 98.62$ & $404.54 \pm 67.13$ & $356.19 \pm 59.78$ & $336.00 \pm 108.87$ & $\begin{array}{c}5.100 / .009 \\
\mathrm{a}>\mathrm{c}^{\dagger}\end{array}$ \\
\hline
\end{tabular}

${ }^{*} p<0.01 ;{ }^{\dagger}<0.05$.

a, sleep more than six hours, traffic accidents Group (Group 1); b, sleep less than six hours, traffic accidents Group (Group 2); c, normal, accident-free group (Group 3). 
Table 3. Differences of sleep habits questionnaire among groups

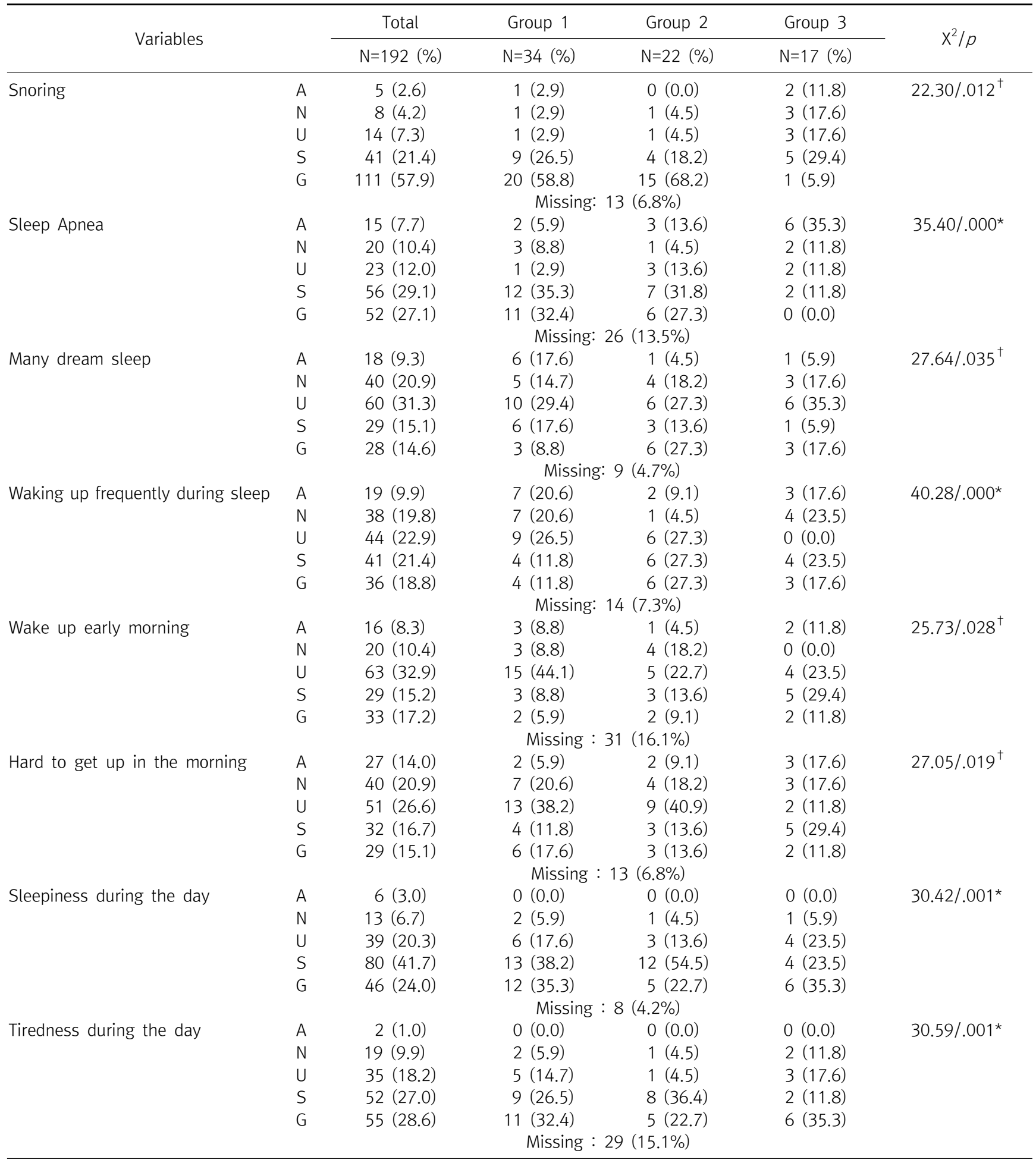

Abbreviation: A, absolutely not; N, no; U, usually; S, slightly; G, greatly.

${ }^{\star} p<0.01 ;{ }^{\dagger}<0.05$.

Group 1, sleep more than six hours, traffic accidents Group; Group 2, sleep less than six hours, traffic accidents Group; Group 3, normal, accident-free group. 
에서도 그룹 간 유의성이 확인되었다.

\section{2. 수면다원검사}

연구대상자들의 수면다원검사에서 수면 분류의 결과는 Table 4와 같이, S1은 그룹 1에서 $28.01 \pm(15.10)$, 그룹 2에서 $20.20 \pm$ (10.12), 그룹 3에서 $11.62 \pm$ (4.94)로 조사되었다. 그룹 별 차이는 그룹 1 과 그룹 2, 그룹 3의 순으로 높았으며, 통계적으로 는 그룹 1과 그룹 3과의 차이가 유의한 결과를 보였다 $(p<0.01) . \mathrm{S} 2$ 의 결과는 그룹 1에서 $51.86 \pm(12.86)$, 그룹 2에서 $59.05 \pm(11.46)$, 그룹 3에서 63.31 (9.51)로 그룹 1과 그룹 2, 그룹 3의 순으로 낮 았으며, 통계적으로는 그룹 1 과 그룹 3 과의 차이가 유의한 결과를 보였다 $(p<0.01) . S 3$ 와 REM sleep은 그룹 간 유의한 차이를 보이 지 않았다. AHI의 결과는 그룹 1에서 36.41 \pm (25.35), 그룹 2에서 $28.44 \pm$ (20.78), 그룹 3에서 3.21 \pm (2.21)로 그룹 별 차이는 그룹 1 과 그룹 2, 그룹 3의 순으로 높았으며, 그룹 1과 그룹 3의 차이가 유의한 결과를 보였다 $(p<0.01)$. 또한, TAI의 결과는 그룹 1 에서 $31.84 \pm(19.27)$, 그룹 2에서 26.21 $\pm(12.06)$, 그룹 3에서 14.21
(7.94)로 나타났고, 그룹 별 차이는 그룹 1과 그룹 2, 그룹 3의 순으 로 낮았으며, 통계적으로는 그룹 1 , 그룹 2의 두 집단 모두 그룹 3 과 유의한 결과를 보였다 $(p<0.01)$.

\section{3. 수면질환 유병율}

연구대상자의 그룹 간 수면장애 유병율을 Table 5에 요약하였 다. 전체 73 명 중 정상소견이 20 명(27.4\%)이고, 53 명(72.6\%)에서 비정상소견을 보였다. 그룹 1의 34 명 중 정상소견은 2 명 $(5.9 \%)$, 비 정상 소견은 32 명 $(94.1 \%)$ 으로 조사되었고, 그룹 2는 정상소견이 1 명(4.5\%), 비정상소견이 21 명 $(95.5 \%)$ 이었다. 그룹 3 의 결과는 17 명 모두 정상이었으며, 그룹 간의 유의한 차이를 보였다 $(p<0.01)$.

\section{4. 졸음운전과 수면 관련 질환}

연구대상자의 졸음운전사고 경험자 그룹 $1+2$ 와사고 경험이 없 으면서 수면다원검사결과 정상 판정을 받은 그룹 3 과의 수면다원 검사결과에 대한 비교 분석은 Table 6과 같다. 얕은 수면 S1은 그룹 $1+2$ 에서 $24.94 \pm 13.81$, 그룹 3은 $11.62 \pm 4.94(p<0.01)$, 중간

Table 4. Differences of the polysomnography among groups

\begin{tabular}{|c|c|c|c|c|c|}
\hline \multirow{2}{*}{ Variables } & Total & Group $1^{a}$ & Group $2^{b}$ & Group $3^{c}$ & \multirow{2}{*}{$\mathrm{F} / \mathrm{p}$} \\
\hline & $N=192$ & $N=34$ & $N=22$ & $\mathrm{~N}=17$ & \\
\hline$S L$ & $10.92 \pm 14.16$ & $6.97 \pm 6.71$ & $25.80 \pm 25.80$ & $13.97 \pm 17.18$ & $1.274 / .286$ \\
\hline $\mathrm{RL}$ & $103.04 \pm 61.30$ & $102.47 \pm 70.78$ & $99.09 \pm 41.31$ & $90.26 \pm 50.49$ & $.245 / .783$ \\
\hline S1 & $23.63 \pm 12.52$ & $28.01 \pm 15.10$ & $20.20 \pm 10.12$ & $11.62 \pm 4.94$ & $\begin{array}{c}10.86 / .000 \\
a>c^{*}\end{array}$ \\
\hline S2 & $54.38 \pm 11.52$ & $51.86 \pm 12.86$ & $59.05 \pm 11.46$ & $63.31 \pm 9.51$ & $\begin{array}{c}6.003 / .004 \\
a<c^{*}\end{array}$ \\
\hline S3 & $2.90 \pm 4.69$ & $1.86 \pm 4.08$ & $3.41 \pm 4.71$ & $5.37 \pm 8.19$ & $2.383 / .100$ \\
\hline REM Sleep & $19.47 \pm 7.84$ & $18.25 \pm 5.51$ & $17.28 \pm 8.38$ & $19.68 \pm 6.36$ & $.620 / .541$ \\
\hline $\mathrm{AHI}$ & $31.71 \pm 23.54$ & $36.41 \pm 25.35$ & $28.44 \pm 20.78$ & $3.12 \pm 2.21$ & $\begin{array}{c}14.64 / .000 \\
a>c^{*}\end{array}$ \\
\hline TAl & $29.44 \pm 16.05$ & $31.84 \pm 19.27$ & $26.21 \pm 12.06$ & $14.21 \pm 7.94$ & $\begin{array}{c}7.55 / .001 \\
a, b>c^{*}\end{array}$ \\
\hline
\end{tabular}

Abbreviation: SL, sleep Latency (normal<15 20 min); RL, REM Latency.

${ }^{\star} p<0.01 ;{ }^{\dagger}<0.05$.

a, sleep more than six hours, traffic accidents group (group 1); b, sleep less than six hours, traffic accidents group (group 2); c, normal, accident-free group (group 3).

S1, Stage 1 (normal<10\%); S2, Stage 2 (normal=44 59\%); S3, Stage 3 (normal=9.5 12\%); REM Sleep, normal=19 26\%; AHI, Apnea Hypopnea Index (normal<10); TAl: Total Arousal Index (normal<10).

Table 5. Results of the prevalence of sleep disorders by groups

\begin{tabular}{|c|c|c|c|c|c|c|}
\hline \multirow{2}{*}{\multicolumn{2}{|c|}{ Variables }} & Total & Group 1 & Group 2 & Group 3 & \multirow{2}{*}{$x^{2} / p$} \\
\hline & & $\mathrm{N}=73(\%)$ & $\mathrm{N}=34(\%)$ & $\mathrm{N}=22(\%)$ & $\mathrm{N}=17 \quad(\%)$ & \\
\hline Sleep & Normal & $20(27.4)$ & $2(5.9)$ & $1(4.5)$ & $17(100)$ & $58.738 / .000 *$ \\
\hline Diagnosis & Abnormal & $53(72.6)$ & $32(94.1)$ & $21(95.5)$ & 0 & \\
\hline
\end{tabular}

${ }^{*} p<0.01 ;{ }^{\dagger}<0.05$.

Group 1, sleep more than six hours, traffic accidents Group; Group 2, sleep less than six hours, traffic accidents Group; Group 3, normal, accident-free group. 
Table 6. Results of the prevalence of sleep disorders by Drowsy driving accident experiences

\begin{tabular}{|c|c|c|c|c|c|}
\hline \multirow{2}{*}{ Variables } & Total & Group $1+2$ & Group 3 & \multirow{2}{*}{$\mathrm{F}$} & \multirow{2}{*}{$\mathrm{t}$} \\
\hline & $N=73$ & $N=56$ & $N=17$ & & \\
\hline SL & $11.60 \pm 17.09$ & $9.23 \pm 17.00$ & $13.97 \pm 17.18$ & .950 & -1.004 \\
\hline $\mathrm{RL}$ & $95.70 \pm 55.49$ & $101.14 \pm 60.50$ & $90.26 \pm 50.49$ & .138 & .673 \\
\hline $\mathrm{S} 1$ & $18.28 \pm 9.37$ & $24.94 \pm 13.81$ & $11.62 \pm 4.94$ & $11.255^{\star}$ & $6.049^{*}$ \\
\hline S2 & $58.99 \pm 11.11$ & $54.68 \pm 12.72$ & $63.31 \pm 9.51$ & 1.090 & $-2.578^{\dagger}$ \\
\hline S3 & $3.92 \pm 6.27$ & $2.47 \pm 4.36$ & $5.37 \pm 8.19$ & $8.966^{\dagger}$ & -1.402 \\
\hline REM Sleep & $18.77 \pm 6.54$ & $17.87 \pm 6.73$ & $19.68 \pm 6.36$ & .006 & -.984 \\
\hline $\mathrm{AHI}$ & $18.20 \pm 13.00$ & $33.28 \pm 23.79$ & $3.12 \pm 2.21$ & $38.764^{\star}$ & $9.352^{*}$ \\
\hline TAl & $21.92 \pm 12.42$ & $29.63 \pm 16.91$ & $14.21 \pm 7.94$ & $4.549^{\dagger}$ & $5.191^{*}$ \\
\hline
\end{tabular}

${ }^{*} p<0.01 ;{ }^{\dagger}<0.05$.

수면 S2는 그룹 $1+2$ 에서 $54.68 \pm 12.72$, 그룹 3은 63.31 9.51 $(p<0.05), \mathrm{AHI}$ 는 그룹 $1+2$ 에서 $33.28 \pm 23.79$, 그룹 3 은 $3.12 \pm 2.21$ $(p<0.01)$ 이었고, $\mathrm{TAI}$ 결과는 그룹 $1+2$ 에서 $29.63 \pm 16.91$, 그룹 3 은 $14.21 \pm 7.94$ ( $p<0.05$ )로 그룹 간 유의한 차이를 보였다. SL, $\mathrm{RL}, \mathrm{S} 3$, REM sleep에서는 그룹 간 유의한 차이가 보이지 않았다.

\section{고 찰}

본 연구는 졸음운전으로 교통사고 또는, 사고의 위험을 경험한 일반 운전자를 대상으로 수면 관련 질환의 유병율을 확인하기 위해 시행하였다. 연구결과, 졸음운전 사고를 경험한 실험 대상자 56 명 의 수면다원검사 결과에서 폐쇄성 수면무호흡증후군 유병율이 그 룹 1에서 32명(94.1\%), 그룹 2에서 21명(95.5\%)으로 나타났으며, 다중수면잠복기검사 결과에서 2 명 $(28.6 \%)$ 이 기면증 진단소견을 보였다. 이러한 결과들은 졸음운전 사고와 수면관련 질환의 유병율 이 높은 연관성 $(p<0.01)$ 이 있다는 것을 증명하였다. 주간 졸음에 대한 선행 연구결과에서도 Sassani 등(2004)은 자동차 사고 위험 성이 정상인 보다 1.7 7.4배까지 증가 된다고 하였으며, Choi와 $\operatorname{Kim}$ (2013)는 기면증은 수면과 각성 주기에 장애가 있는 질환으로 주간졸음증을 유발한다고 하였다. Kang 등(2011)은 폐쇄성 수면 무호흡증후군(OSA; obstructive sleep apnea)이 대표적인 수면 분절의 원인으로 잠을 자는 동안 심한 코골이와 무호흡으로 수면장 애를 일으키고, 낮에 심한 졸림과 피로감을 일으킬 수 있다고 보고 하였고, Shiomi 등(2002)도 수면무호흡증에 의한 주간 졸음으로 교통사고나 업무 중에 위험을 증가 시키는 것으로 보고하였다.

수면다원검사 결과에서도 그룹 1은 그룹 3과 S1 ( $p<0.01), \mathrm{S} 2$ $(p<0.01), \mathrm{AHI}(p<0.01), \mathrm{TAI}(p<0.01)$ 등의 결과에서 그룹2 보 다 증가되어 있었으며, 수면의 질이 떨어지는 것으로 조사되었다. 따라서 이러한 결과로 볼 때, 그룹 2 의 일시적인 수면부족으로 인한 교통사고 보다 정상 시간의 수면을 취하고도 수면관련 질환 때문에
생기는 주간졸음증의 영향으로 졸음교통사고를 유발하는 그룹1에 주목할 필요가 있다고 사료된다. 이와 관련하여 Kim과 $\mathrm{Kim}$ (2007)은 AHI와의 상관관계는 목둘레가 체질량지수보다 더 높았 으며 이는 폐쇄성수면무호흡-저호흡 증후군의 원인으로 전반적인 비만도 보다 목과 상기도의 국소적인 지방의 두께가 더 중요할 뿐 만 아니라 혈압(Kim, 2014), 염증반응(Lee와 Kim, 2015)과의 연 관성을 찾을 수 있을 것으로 사료된다. 한편 체위성 수면무호흡 환 자는 경증과 중증도 환자에서 두드러지며, 체위성 환자의 중요 지 표는 나이와 REM \%가 증가할수록, 무호흡-저호흡지수가 감소할 수록 체위성 환자로 보고한 결과와 유사성을 찾을 수 있었다 $(\mathrm{Kim}$ 등, 2012).

수면습관에 대한 설문에서는 잠자는 동안 얼마나 자주 깨는지 (그룹2>그룹1>그룹3) $(p<0.01)$, 한번 잠에서 깬 후 다시 잠들기 얼마나 어려운지(그룹1>그룹2>그룹3) $(p<0.05)$, 아침에 얼마 나 빨리 깨는지(그룹 $1>$ 그륩 $2>$ 그룹 3 ) $(p<0.05)$, 아침에 일어나 기 어려운 정도(그룹 $1>$ 그룹 $2>$ 그룹 3 ) $(p<0.05)$, 낮에 졸리운 정 도(그룹1>그룹2>그룹3) $(p<0.01)$, 낮에 피곤한 정도(그룹1> 그룹 $2>$ 그룹 3$)(p<0.01)$ 를 묻는 질문에 그룹 간 유의한 차이를 보 였다. 이러한 결과들을 토대로 수면 질환과 관련된 주간졸음증을 사전에 감별을 할 수 있는 설문지를 개발한다면, 주간졸음증에 대 한 척도로 활용이 가능하고, 설문 분석을 통해 수면질환에 대한 치료 를 받을 수 있게 유도할 수 있는 용도로 사용할 수 있다고 생각한다.

일반적으로 졸음운전을 전반적인 수면시간의 부족, 즉 제한된 수면으로 평가하여 졸음쉼터 설치와 같이, 충분한 휴식을 취하고 운전을 하도록 안내 및 홍보를 하고 있는 수준이지만, 교통사고의 치사율과 관련된 심각한 문제는 수면관련 질환에 의한 수면의 분절 로 졸음운전을 하게 되는 경우를 간과하고 있다고 생각한다. 향후 에는 졸음운전 사고경험자를 대상으로 수면다원검사와 다중수면 잠복기검사를 시행하여 수면 관련 질환의 유병률을 분석하는 역학 조사가 진행될 수 있기를 기대한다. 
결론적으로 졸음운전 교통사고 경험자 56명(그룹 $1+2)$ 의 $94.6 \%$ (53명)에서 수면 질환에 유병률을 보였고, 그룹 $1+2$ 는 그룹 3 보다 많은 정상적인 수면시간을 가졌음에도 깊은 수면(S3)의 분포는 적 고, 얕은 수면(S1)이 증가되어 있었으며, TAI, AHI 지수는 높아져서 수면의 질은 떨어져 있었다.

\section{요 약}

본 연구는 졸음운전 사고 경험자들의 수면관련 질환에 관한 유 병율을 조사하기 위하여 설문에 응답한 192명 중에서 정상수면 후 사고 경험자 34 명(그룹 1), 비 정상수면 후 사고 경험자 22명(그룹 2), 수면다원검사 결과가 정상이면서 사고 경험이 없는 17 명(그룹 3)을 대상으로 평상 시 수면습관에 대한 설문 결과와 수면다원검 사, 다중수면잠복기검사 결과를 비교 분석하였다. 수면습관에 대 한 설문에서 잠자는 동안 얼마나 자주 깨는지 $(p<0.01)$, 한번 잠에 서 깬 후 다시 잠들기 얼마나 어려운지 $(p<0.05)$, 아침에 얼마나 빨 리 깨는지 $(p<0.05)$, 아침에 일어나기 어려운 정도 $(p<0.05)$, 낮에 졸리운 정도 $(p<0.01)$, 낮에 피곤한 정도 $(p<0.01)$ 에서 그룹 간 유 의성이 확인되었다. 또한, 졸음운전 교통사고 경험이 있는 연구대 상자 56명 중, $94.6 \%(53$ 명)에서 수면 관련 질환이 확인 되었다. 따 라서 졸음운전 교통사고가 단순하게 일시적 수면부족만이 원인이 아니라 수면시간이 충분해도 수면관련 질환의 영향으로 주간졸음 증이 발생하고, 그로 인해 교통사고 등이 발생한다는 것을 확인하 였다. 따라서 본 연구는 졸음운전 교통사고와 수면 관련 질환 사이 의 연관성에 대해 확인해 보는 것에 의의가 있었다. 또한 이 데이터 들은 수면질환과 관련된 졸음운전에 대하여 사회적 대책 마련을 강 구하는데 필요한 기초 자료가 되리라고 사료된다.

\section{Acknowledgements: None}

Funding: None

Conflict of interest: None

\section{References}

1. Choi SJ, Kim KS. Structural equation modeling on health-related quality of life in patients with obstructive sleep apnea. $J$ Korean Acad Nurs. 2013, 43:81-90.

2. Collop N. The effect of obstructive sleep apnea on chronic medical disorders. Cleve Clin J Med. 2007, 74:72-78.

3. Jo GH, Lee MS. The relation of commercial motor vehicle driver's fatigue and traffic accident. Korean Review of Crisis and Emergency Management. 2014, 10:1-14.

4. Kang SG, Kim SH, Park SJ, Kim HN, Park YJ, Song SW. The effects of non-surgical weight reduction on daytime sleepiness and fatigue in patients with obstructive sleep anpea. Journal of Korean Society for the Study of Obesity. 2011, 20:177-184.

5. Kim CS. The association between blood pressure and obstructive sleep apnea-hypopnea syndrome. Korean J Clin Lab Sci. 2014, 46:106-110.

6. Kim CS, Kim DS. Correlation of body mass index and neck circumference in patients with obstructive sleep apnea-hypopnea syndrome. Korean J Clin Lab Sci. 2007, 39:141-146.

7. Kim CS, Lee YS, Cho CU, Pae SH, Lee SA. The prevalence and characteristics of positional obstructive sleep apnea. Korean J Clin Lab Sci. 2012, 44:52-58.

8. Lee SH. Drowsy driving and traffic accidents. Sleep Med Psychophysiol. 2003, 10:84-87.

9. Lee SJ, Kim J. Inflammation and insufficient or disordered sleep. Korean J Clin Lab Sci. 2015, 47:97-104.

10. Pandi-Perumal SR, Verster JC, Kayumov L, Lowe AD, Santana MG, Pires ML, et al. Sleep disorder, sleepiness and traffic safety: a public health menace. Braz J Med Biol Res. 2006, 39:863-871.

11. Sassani A, Findly L, Kryger M, Goldlust E, George C, Davidson T. Reducing motor-vehicle collisions, costs, and fatalities by treating obstructive sleep apnea syndrome. Sleep. 2004, 27:453458.

12. Shiomi T, Arita AT, Sasanabe R, Banno K, Yamakawa H, Hasegawa R, et al. Falling asleep while driving and automobile accidents among patients with obstructive sleep apnea-hypopnea syndrome. Psychiatry Clin Neurosci. 2002, 56:333-334.

13. Siedlecka J, Bortkiewicz A. Driving simulators in risk assessment of traffic accident among drivers with obstructive sleep apnea. Med Pr. 2012, 63:229-236.

14. Ward KL, Hillman DR, James A, Bremner AP, Simpson L, Cooper $\mathrm{MN}$, et al. Excessive daytime sleepiness increases the risk of motor vehicle crash in obstructive sleep apnea. J Clin Sleep Med. 2013, 9:1013-1021. 